\title{
Strategies in highlighting paleo research
}

\author{
Estelle Razanatsoa', Y. Ait Brahim² and N. Schafstall ${ }^{3}$
}

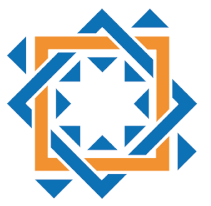

PAGES Morillo de Tou 2017

3rd Young Scientists Meeting

Global Challenges for our Common Future

a paleoscience perspective

Environmental change is being experienced worldwide; its extent and variation, however, are still poorly documented. In order to better understand the present-day environmental change and to predict the impact on ecosystems of climate and human social behavior, it is important to learn about the natural variability of Earth's ecosystems and the mechanisms behind these changes. Paleo research provides information on the causal factors and the succession of environmental and climatic events at annual to millennial time scales. However, many paleo studies are descriptive and provide little practical application from the socioeconomic point of view. Several ideas might help highlighting paleo research as a useful tool to solve problems of socio-economic importance.

Paleoscientists need to understand the relevance of their research in solving specific present-day problems to enhance the public interest in the discipline. For example, paleoecological records describe how vegetation has changed and responded to various forms of disturbance such as fire or herbivores over time. By unraveling past vegetation patterns, baselines can be set to mark the development of a peatland, a nature reserve or a region. Such baselines are valuable to disentangle challenges of ecosystem degradation, species disappearance and species invasion. Relating those findings from the past with the current issues of ecosystem management would play an important role in positioning paleo research in the domain of conservation.

Communication of paleoscience to the general public and other stakeholders, like contributors of ecosystem services and governments, is also a key strategy to highlight its importance. Often, paleoscientists find it challenging to communicate their results to non-experts due to their complexity. In many cases, people have never met an actual researcher and do not understand the motivations behind paleo research. Therefore, it might be easier to engage with the general public by providing historical, humanrelated examples of environmental change such as drought or floods, and by showing how paleo research can evaluate their frequency and their probability of return on a longer time scale. However, this approach might not be applicable to socio-economic stakeholders as their interest is centered in tangible results like economic models or cost calculations.
Long-term environmental data could also be used to assess the economic value of ecosystem services. In fact, society is dependent on the services and goods offered by ecosystems and these services are explicitly expressed financially. Paleo research shows the long-term state of these services and goods that allow the assessment of the potential threats and the possibility to evaluate their sustainable use. When presenting their results, paleoscientists need to be aware of the quantifiable information they provided in terms of their monetary value. It is then crucial to associate the paleo data with the monetary assessment of modern analogues through collaboration with stakeholders. For instance, paleo research provides a long-term and large-scale view of the climate variability, as it explains its impact on socio-economic issues. In fact, continental or global data on a longer time scale would be more valuable to decision makers like NGO's, despite the fact that local case studies are relevant to local stakeholders for their own assessment. In addition, direct cooperation with socio-economical actors would enhance the ability of paleoscientists to interpret their data to solve present-day problems and might promote interdisciplinary projects that serve both research and its direct applications to the society. Since it can be difficult to show the prospective results of a paleo research project, it might even be worth collaborating with marketing or communication specialists to pitch the highlights and benefits of paleo research to all involved socio-economic stakeholders.

Despite current challenges, it is possible to highlight the importance of paleo research in solving present-day socio-economic problems. This could be achieved by understanding the different motivations of the various stakeholders and by adequately crafting the communication for the audience. The overall value of the services and goods should be measured against paleo research, and international and interdisciplinary collaborations should be favored.

\section{AFFILIATIONS}

'Department of Biological sciences, University of Cape Town, South Africa

${ }^{2}$ Laboratory of Applied Geology and

Geo-Environment, Ibn Zohr University, Agadir, Morocco

${ }^{3}$ Department of Forest Ecology, Czech University of Life Sciences in Prague, Czech Republic

\section{CONTACT}

Estelle Razanatsoa: estellebota@gmail.com

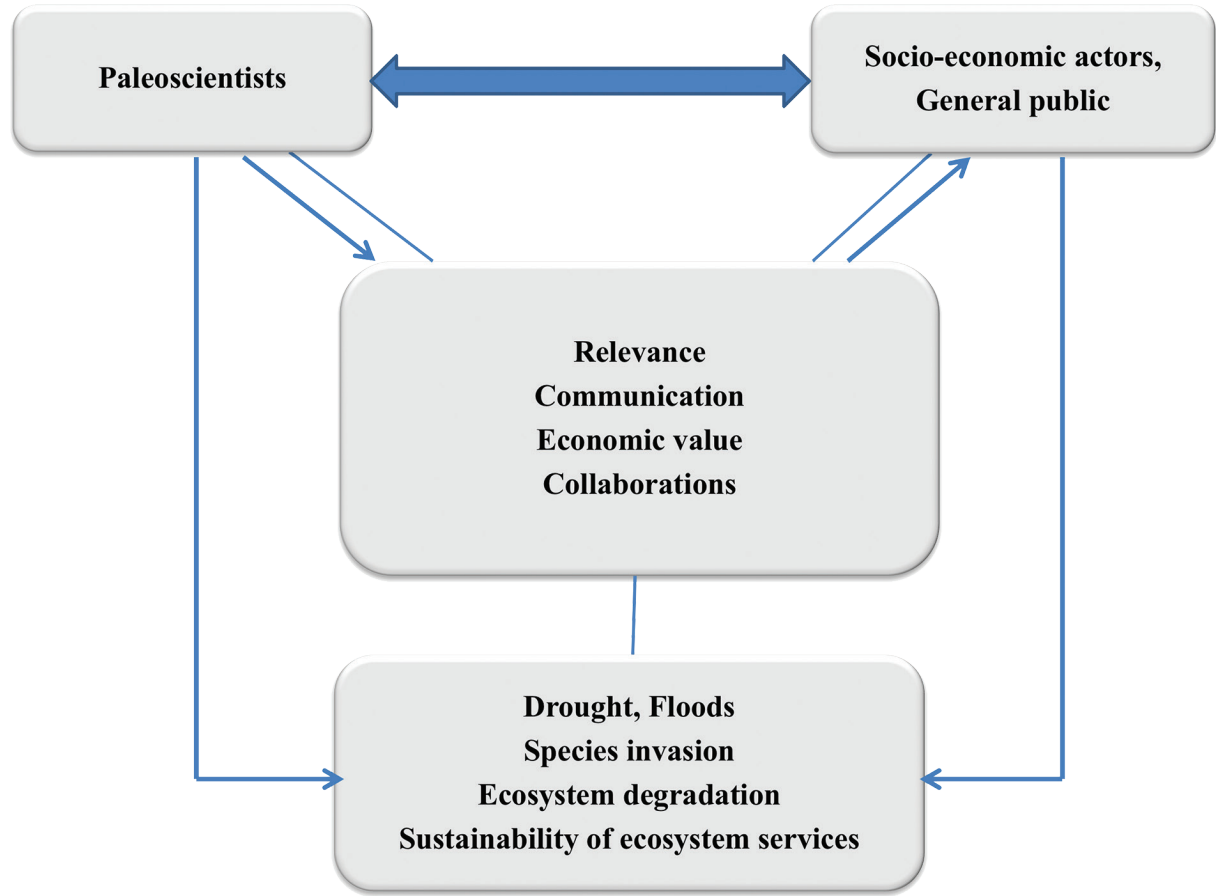

Graph of the interactions between the different actors for developing better strategies to highlight paleo research as a useful tool to solve present-day problems of socio-economic importance. This graph is an outcome of the breakout discussion during PAGES 3rd Young Scientists Meeting in Spain in May 2017. 